\title{
Fluência e acurácia em ouvintes usuários de Libras como segunda língua: autoavaliação de acadêmicos do Letras Libras
}

\author{
Lídia da Silva ${ }^{1}$ \\ lidiaufpr@gmail.com \\ Marianne Rossi Stumpft ${ }^{2}$ \\ stumpfmarianne@gmail.com
}

\section{Resumo}

O presente trabalho tem por objetivo cruzar os dados da autoavaliação sobre fluência e acurácia dos acadêmicos do Letras Libras (Língua Brasileira de Sinais) com as abordagens teóricas destes conceitos. Para tanto, aplicamos um questionário semiestruturado dirigidos a 50 alunos ouvintes inseridos no contexto universitário, tanto do bacharelado quanto da licenciatura. Nossos resultados apontam tratar-se de um conceito bastante multifacetado. Isso quer dizer que, um mesmo sinalizante ouvinte pode ser considerado como fluente ou disfluente a depender da perspectiva adotada por quem avalia, inclusive por ele mesmo. Além disso, analisamos a autoavaliação tendo como pano de fundo o entendimento de que acadêmicos de um curso de formação de professores e tradutores de Libras precisam relativizar as perguntas genéricas e avançar na especificidade dos conceitos. Sobre acurácia, nossos dados apontam para necessidade dos ouvintes revisitarem o conceito e aperfeiçoarem a autocrítica sobre a produção.

1 Professora do Curso de Letras Libras da Universidade Federal do Paraná e doutoranda do Programa de Linguística da Universidade Federal de Santa Catarina.

2 Professora da Universidade Federal de Santa Catarina e orientadora de tese da primeira autora. 
Palavras-chave: Acurácia. Fluência em Libras. Ouvintes usuários de L2.

\begin{abstract}
This study aims to cross the data of self-assessment on fluency and accuracy of individuals with a degree in Brazilian Sign Language - Libras - with the theoretical approaches of these concepts. Therefore, we apply a semi-structured questionnaire to listeners 50 students are the university context. Our results show that this is a very multifaceted concept. This means that the same a individual can be considered as fluent or disfluente depending on the perspective adopted by those who evaluate, including himself. In addition, we analyze the self-evaluation with the background of the understanding that academics from a teacher training course and Libras translators need to relativize the general questions and advance specific concepts. About accuracy, our data point to the need listeners revisit the concept and to perfect the self-criticism on production.
\end{abstract}

Keywords: Accuracy. Fluency in Libras. Users listeners as L2.

\title{
Introdução
}

Desde 2002, com o reconhecimento da Libras pela Lei 10.436, tem havido a disseminação do idioma em território nacional. Esta legislação favoreceu o desenvolvimento de políticas de incentivo de seu ensino às pessoas ouvintes, principalmente em espaços públicos. Entretanto, dado o pouco tempo de implementação desta realidade, constatamos a ausência de uma tradição consolidada para o ensino de Libras no Brasil e por isso mesmo o que tem acontecido são práticas docentes de base empírica.

O Decreto 5626/2005, além de regulamentar diferentes aspectos relativos ao uso e difusão da Libras em território nacional, aponta 
diretrizes para formação profissional de intérpretes ou professores desta língua e a implementação do curso superior em Letras Libras se refere a uma ação implementada.

Este curso imprime importantes políticas linguísticas em relação à língua quando, por exemplo, as instituições públicas federais que têm oferecido esse curso superior promovem o vestibular em Libras, ou seja, o domínio da língua é pré-requisito para ingresso do candidato. Outra questão é o fato de que os candidatos que se submetem a este processo seletivo e que passam a cursar a graduação recebem aulas em Libras visto que a maioria dos professores é composta por surdos ou ouvintes fluentes na língua, logo, toda interação e aprendizagem são mediadas por esta língua. Com este contexto, podemos considerar que os sujeitos ouvintes usuários ${ }^{3}$ de Libras como segunda língua conseguem se comunicar neste idioma.

Nesse sentido, este estudo foca nas pessoas ouvintes que são acadêmicas do curso Letras Libras uma vez que, empiricamente, se constata que se tornar fluente nesta língua não tem sido uma constante na realidade brasileira, e tal fato tem causado efeito prejudicial à comunidade surda que, em última instância, necessita de uma comunicação eficaz com os cidadãos conterrâneos, por isso, pensamos que com a reflexão a respeito do tema, poderemos apontar importantes caminhos metodológicos para o ensino da Libras como segunda língua.

Dessa forma, a presente pesquisa traz ampliação de estudos na área de linguística e línguas de sinais (Libras), contribui para a melhoria da descrição linguística dos aspectos da acurácia e fluência no aprendizado da Libras para ouvintes e cria subsídios teórico-metodológicos para compreensão dos fatores envolvidos na aquisição da Libras por parte dos ouvintes.

3 Usuário neste texto é entendido como a pessoa que sinaliza e não aquela que se serve da língua como instrumento. Isso quer dizer, que apesar do termo, a visão não é utilitarista. 


\section{Metodologia}

Esse estudo não se preocupa com representatividade numérica, mas, sim, com a compreensão que um grupo de pessoas tem a respeito da fluência e da acurácia da sua sinalização, por isso, a pesquisa é de base qualitativa. Este tipo de pesquisa tem como objetivo proporcionar maior familiaridade com o tema, com vistas a torná-lo mais explícito ou a construir hipóteses. Nossa pesquisa é descritiva, pois evidencia respostas de um grupo pesquisado e as analisa à luz de concepções de diversos autores. Nosso artigo adota os procedimentos de survey, pois busca informação diretamente com um grupo de interesse a respeito dos dados que se deseja obter.

A pesquisa com survey pode ser referida como sendo a obtenção de dados ou informações sobre as características ou as opiniões de determinado grupo de pessoas, indicado como representante de uma população-alvo, utilizando um questionário como instrumento de pesquisa (FONSECA, 2002). Nesse tipo de investigação, o respondente não é identificável, portanto o sigilo é garantido. Como exploratória que é, esta pesquisa pretende cruzar os dados da autoavaliação com os conceitos de fluência e acurácia em acadêmicos do Letras Libras. Para tanto, procedemos com a coleta de dados in loco.

\section{Coleta de dados}

A Universidade Federal de Santa Catarina - UFSC e a Universidade Federal do Paraná - UFPR oferecem o curso de Letras Libras. A primeira, com habilitação em licenciatura e bacharelado e a segunda com habilitação em licenciatura. Em ambas as instituições há a presença de surdos e ouvintes, entretanto, nossa pesquisa selecionou apenas os ouvintes aos quais solicitamos o preenchimento do termo de consentimento livre 
e esclarecido. Na UFSC, aplicamos o questionário a alunos que fazem o curso na modalidade presencial e a alunos que fazem o curso na modalidade à distância, no Polo de Joinville/SC. Na UFPR não há curso à distância. Quanto a aplicação, as pesquisadoras estavam presentes em sala e, entregaram o papel impresso aos participantes e quando solicitadas, ofereceram assistência para o preenchimento.

\section{Tratamento dos dados e categorias de análises}

Trabalhamos com dois tipos de fontes: o questionário de autoavaliação sobre fluência e acurácia e uma breve discussão teórica sobre tais conceitos para que pudéssemos fazer a triangulação de dados. Tratar dos dados nessas duas categorias nos pareceu vantajoso, do ponto de vista científico, uma vez que pudemos perceber algumas discrepâncias entre as respostas obtidas e os fundamentos teóricos relativos à linguística, campo do conhecimento em que se assenta o curso de Letras Libras.

\section{Os sujeitos da pesquisa: descrição e análise}

Os sujeitos participantes da pesquisa são na maioria do bacharelado, nos primeiros períodos do curso, e têm entre 18 a 25 anos de idade. 


\section{Perfil dos participantes: Habilitação do Curso de Letras Libras}

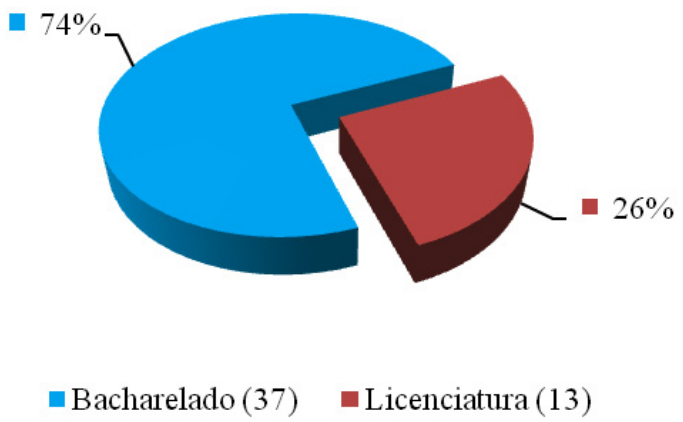

Gráfico 1 - Perfil dos participantes: habilitação do Curso de Letras Libras

\section{Perfil dos participantes: Período Curso de Letras} Libras

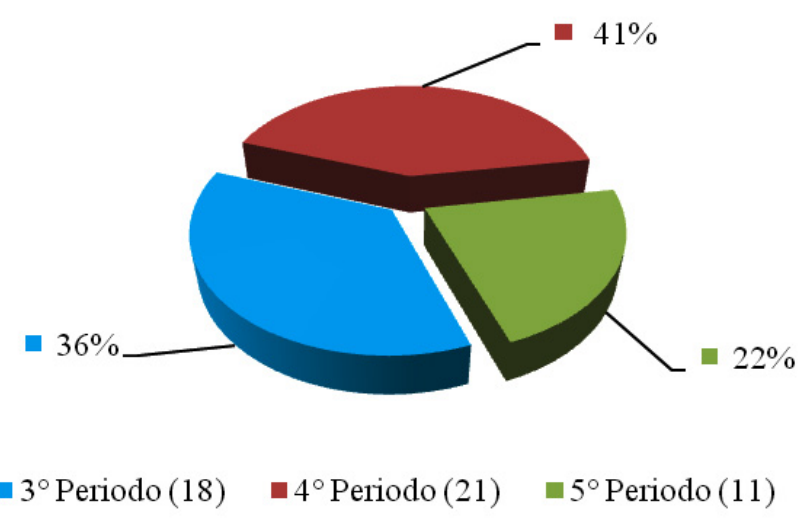

Gráfico 2 - Perfil dos participantes: período Curso de Letras Libras 


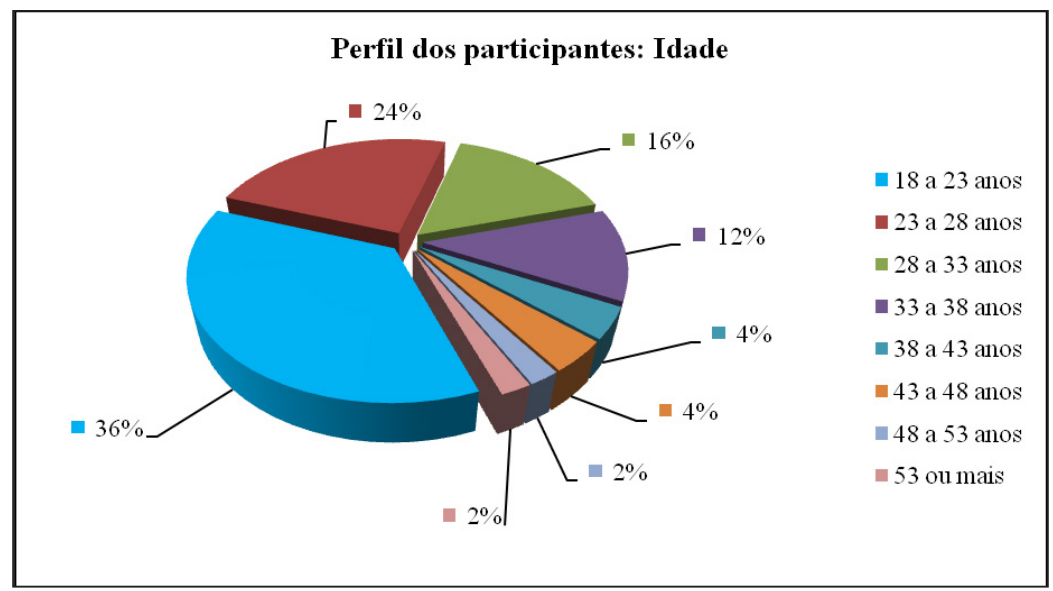

Gráfico 3 - Perfil dos participantes: idade

Em relação ao conhecimento que eles têm da Libras, perguntamos: 'você sabe Libras' e obtivemos os seguintes resultados:

\section{Perfil dos participantes: Sabe Libras?}

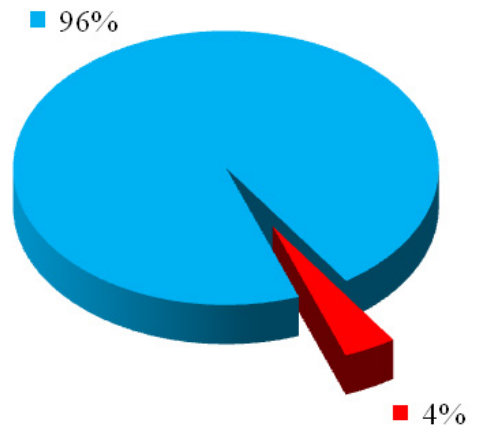

घ Sim — Não

Gráfico 4 - Perfil dos participantes: Sabe Libras? 
Sabemos que o conceito de 'saber uma língua' varia, primeiro, de acordo com o conceito que se tem de língua. Se a concepção é saussuriana, possivelmente, o 'saber' a língua vai estar relacionado ao domínio das regras do sistema linguístico, já se a concepção for funcional, então, o 'saber' a língua vai estar relacionado às funções comunicativas e assim sucessivamente. Para nós, a pergunta 'Você sabe Libras' era randômica no questionário. Isso porque, se adotarmos, por exemplo, o conceito de Scaramucci (2000) para 'saber uma língua' vamos relacioná-lo as habilidades de compreensão e produção. E nesse caso, compreender e produzir a modalidade sinalizada da Libras impõe ainda a necessidade de se delimitar um escopo de uso já que o contexto pode determinar o resultado comunicativo. Nenhum falante de português, por exemplo, ainda que fluente, se sairá bem na compreensão e na produção de um texto cuja temática seja tecnicamente fora do seu contexto. Da mesma forma, dificilmente um falante de língua estrangeira apresentará habilidade de compreensão e produção oral em um texto em que a abordagem seja muito específica. Ao contrário, por exemplo, de pesquisadores de determinada área que fazem leituras em língua estrangeira de textos que trazem à tona assuntos que lhe são conhecidos, podem apresentar habilidade de compreensão e produção daquele texto.

$\mathrm{Na}$ pergunta em tela, não temos a especificação de nenhum escopo de aplicação de tais habilidades, e por isso, o dado pode ser problematizado uma vez que o entrevistado pode enunciar que 'sabe a Libras' mas não ser capaz de compreender um texto sinalizado que seja muito técnico uma vez que ele, diariamente, utiliza sinais com pouca complexidade ou não seja capaz de produzir um discurso acadêmico uma vez que se encontra nos primeiros estágios da aquisição da língua, e por isso, tem contato com insumos informais. Da mesma forma, aqueles entrevistados que disseram não saber a língua podem ser capazes de estabelecer comunicação em Libras, em uma dada situação, haja vista que conseguiram avançar para além do primeiro período de um curso 
cujas atividades são, prioritariamente, sinalizadas. Os que disseram não saber Libras, explicaram que só sabem o português sinalizado. Para nós, comunicar-se com português sinalizado demonstra certo estágio na interlíngua e não um desconhecimento da Libras.

Nossa hipótese para esta questão era que os entrevistados fossem se autodeclarar como conhecedores da língua, mas o fato de não haver nenhuma observação no questionário e o fato de não ter sido feita nenhuma pergunta as aplicadoras da pesquisa, nos faz pensar se os acadêmicos, somente ficaram constrangidos com a pergunta ou se, realmente, não refletiram sobre a temática e de forma, ingênua responderam a questão, tal qual o fazem aqueles que não são especialistas nos estudos de uma língua.

Após investigarmos a autoavaliação e autodeclaração sobre o conhecimento da língua, questionamos 'há quanto tempo sabe Libras' e obtivemos os seguintes resultados:

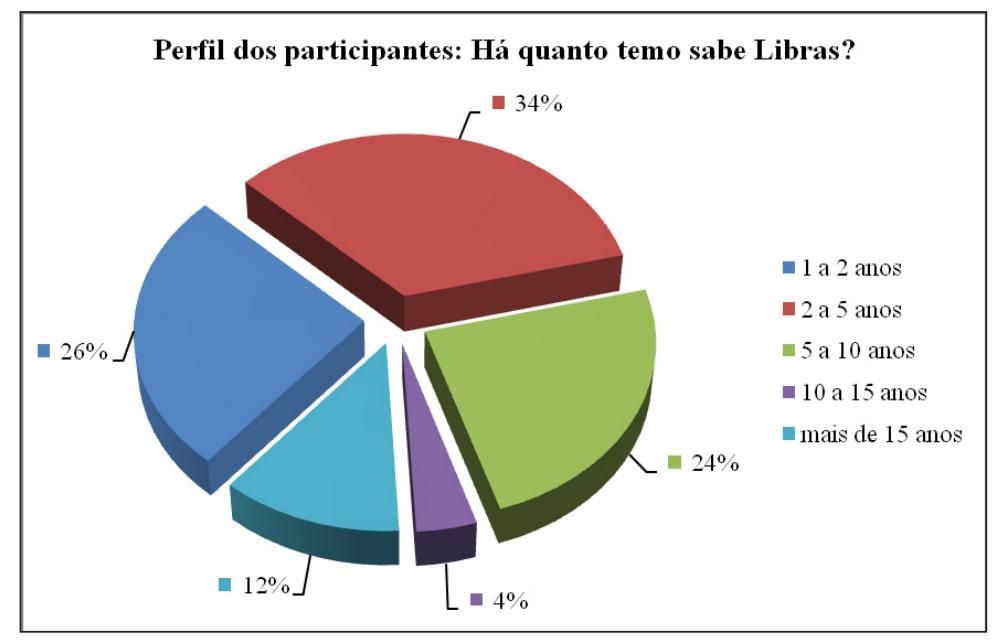

Gráfico 5 - Perfil dos participantes: Há quanto temo sabe Libras?

Esse dado também nos mostra que do universo de 50 pessoas entrevistadas, 30\% delas está aprendendo Libras em um contexto formal de ensino, ou seja, no curso de Letras Libras, uma vez que apontam a 
coincidência de tempo de aprendizado da língua com o tempo de estudos no ensino superior. O perfil deste grupo também nos mostra que 17,5\% de sinalizadores vem a academia à procura de uma certificação para fins desconhecidos por nós, mas que indicam que as atuais políticas públicas de incentivo a profissionalização na área tem atraído também pessoas pertencentes a mais de dez anos na comunidade surda. Outro fator que demonstra a exposição dos aprendizes à língua foi identificado na pergunta "Quantas vezes você fala em Libras durante a semana?". Vejamos nosso resultado:

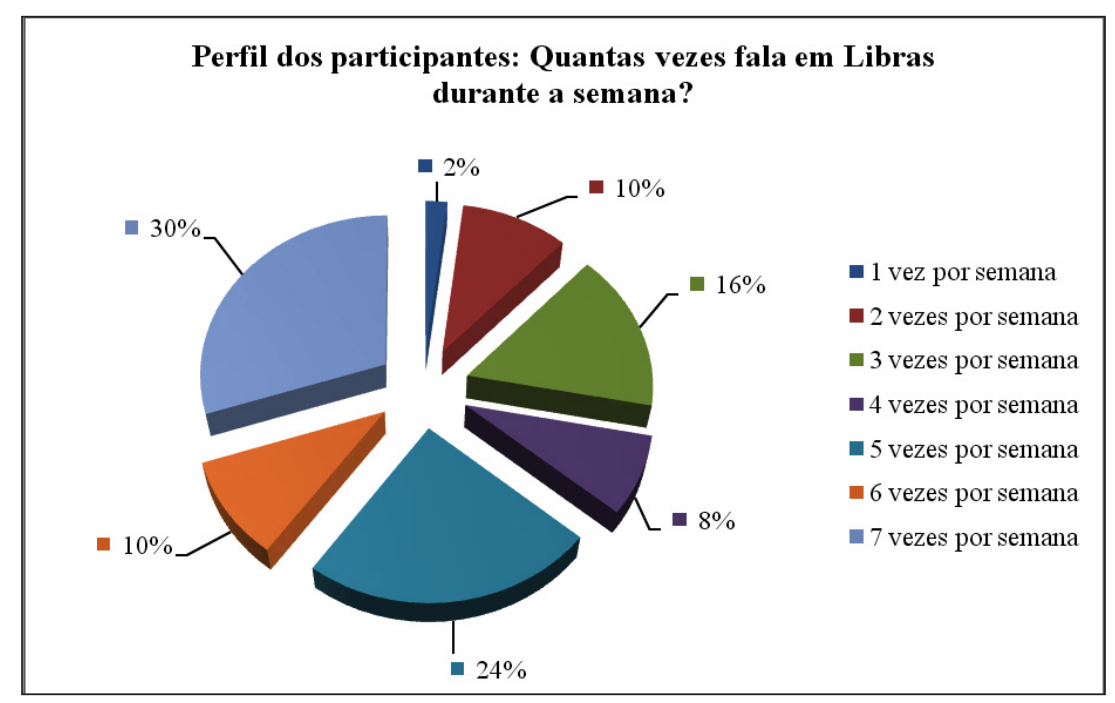

Gráfico 6 - Perfil dos participantes: Quantas vezes fala em Libras durante a semana?

Percebemos que um número expressivo de entrevistados tem contato diário com a língua, isso porque, o contexto de investigação favoreceu tal dado, uma vez que no curso de Letras Libras as aulas são ministradas nesse idioma. Há aqueles que, provavelmente por razões pessoais, tem contato com a língua nos finais de semana. Quanto se pediu 
aos entrevistados para avaliarem o seu nível de conhecimento em Libras, obtivemos as seguintes respostas:

\section{Perfil dos participantes: Nível de conhecimento em Libras}

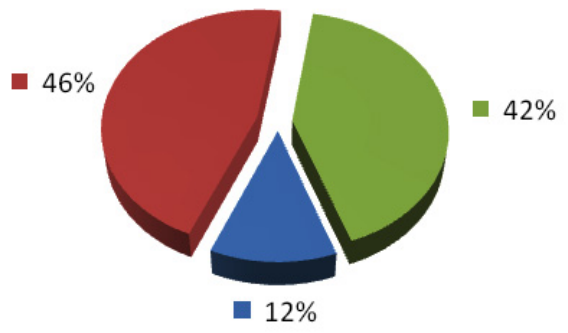

- Basico Intermediario $\quad$ Avançado

Gráfico 7 - Perfil dos participantes: Nível de conhecimento em Libras

Essa é uma pergunta bastante capciosa uma vez que não há no Brasil nenhum teste regulamentado para medir níveis de fluência de falantes de Libras como L2, então, a autoavaliação deve estar baseada em critérios particulares e não institucionalizados.

É interessante observar a equiparação entre os níveis intermediários e avançados da maioria dos entrevistados. Como não se trata de entrevista aberta não tivemos a oportunidade de saber o que levou esses acadêmicos a registrarem tais respostas. Ficamos, apenas, com uma dúvida a respeito da não problematização das categorias apresentadas. Mais uma vez, oferecemos uma questão randômica e os entrevistados, não questionaram e apenas assinalaram a forma que se autoavaliam. Provavelmente eles têm algum conceito do que significa cada um dos níveis, derivados de cursos ou afins, mas nosso estudo não dá conta de analisar as concepções implícitas, apenas levanta pontos para o debate.

Isso posto, passeamos a primeira triangulação dos dados. 


\section{Fluência em ouvintes usuários de Libras como segunda língua}

A língua portuguesa é uma língua de modalidade oral e auditiva. Ela é a primeira língua das pessoas ouvintes nascidas no Brasil, língua que os falantes dominam e transitam em diferentes gêneros. Mas e em relação à segunda língua? Quando se trata de segunda língua há um tema central a ser debatido que é questão do desenvolvimento da fluência nesse idioma que não é o seu nativo. E sobre fluência, Silva (2000) aponta que se trata de conceito bastante multifacetado. Isso porque, além de raros, os estudos existentes sobre a temática, dificilmente são convergentes. Apesar de o campo da aquisição da linguagem reconhecer a importância e a relevância epistemológica desse fenômeno, ele tem sido deixado à margem ou tem sido tomado por um silêncio embaraçoso nas literaturas correntes.

Se é assim com línguas orais, o que dizer, do estudo da fluência de uma língua cuja modalidade é espaço visual como a Libras? Por conta da raridade de discussão teórica sobre a temática na linguística das línguas de sinais, falaremos, neste texto, do mesmo lugar discursivo em que se alojam os estudos sobre fluência em línguas orais, especialmente, o inglês.

Comecemos pela distinção das abordagens sobre fluência, qual seja: a distinção entre enfoques quantitativo e qualitativos. As quantitativas são medidas por meio de índices de produção enquanto as qualitativas consideram também o contexto, mas sabemos que mesmo dentro da mesma abordagem há inúmeras discordâncias conceituais.

$\mathrm{Na}$ abordagem quantitativa, a fluência pode ser vista como rapidez ao falar, uma fluidez contínua, com pouca hesitação. Conforme Skehan e Foster (2001), a fluência é a capacidade do falante de produzir linguagem em tempo real sem pausas ou hesitações em excesso e em caso de adotarmos esta perspectiva, vamos considerar que, pelo menos 7\% dos acadêmicos do Letras Libras não seriam fluentes, uma vez que disseram que sempre dão pausas ou hesitam durante a sinalização. 


\section{Frequência de pausa e hesitação durante a sinalização dos acadêmicos do Letras Libras}

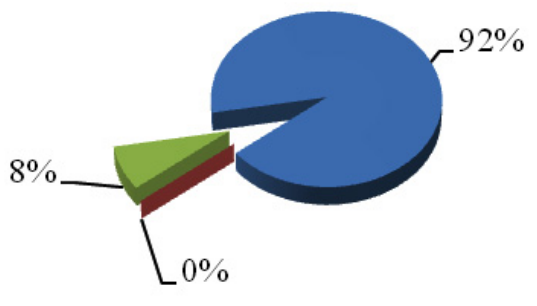

Sempre $\square$ Nunca $\square$ Asvezes

Gráfico 8 - Frequência de pausa e hesitação durante a sinalização dos acadêmicos do Letras Libras

Ocorre que, muitas vezes, as pessoas não falam rápido, não por não serem fluentes, mas por preferirem priorizar a escolha lexical em detrimento a fluidez, por exemplo. Acontece que a hesitação é um fenômeno presente em praticamente todas as falas, exceto aquelas extremamente ensaiadas e os gestos fonéticos são adaptativos e maleável ás demandas de mudança de estilo de fala de rápido para vagaroso, baixo para alto, informal para claro, bem articulado, íntimo, público. Falamos de modo diferente quando nos dirigimos a estrangeiros, bebês, computadores e pessoas idosas. Modulamos nossa fala, mesmo involuntariamente, em resposta a fatores fisiológicos e emocionais.

A variação fonética abunda se compararmos amostras de fala de um mesmo indivíduo ou vários falantes. Ou seja, a hesitação e a pausa não podem ser mal vista, pois ela não é sinônimo de erro, mas $100 \%$ dos acadêmicos (93\% que as vezes dão pausas e hesitam e os $7 \%$ que sempre dão pausas e hesitam) disseram ter atitude corretiva frente ao fenômeno. 
Eles dizem pedir desculpas ou se corrigirem. A questão que nos intriga é: os acadêmicos se corrigem do que? Pedem desculpas do que? Ao que parece os ouvintes não notaram que os surdos - potenciais usuários de Libras como L1 - normalmente fazem pausa preenchidas, por meio de movimentos com as mãos que não tem significado lexical e, ao contrário de ser um erro, demonstra domínio articulatório para produção linguística, portanto, não faz sentido nenhum um pedido de desculpa frente à pausa e/ou hesitação.

Ainda visando instigar os acadêmicos a respeito da pausa, os arguimos sobre os momentos em que eles deixam suas mãos em repouso e 100\% dos entrevistados nos responderam que suas mãos ficam em repouso apenas quando o interlocutor está com turno de fala. Isso nos mostra, mais uma vez que a concepção que parece estar presente é aquela de preenchimento constante de fala. E para sabermos o fluxo dessa sinalização constante, os perguntamos sobre o ritmo da fala e as respostas que obtivemos foram essas:

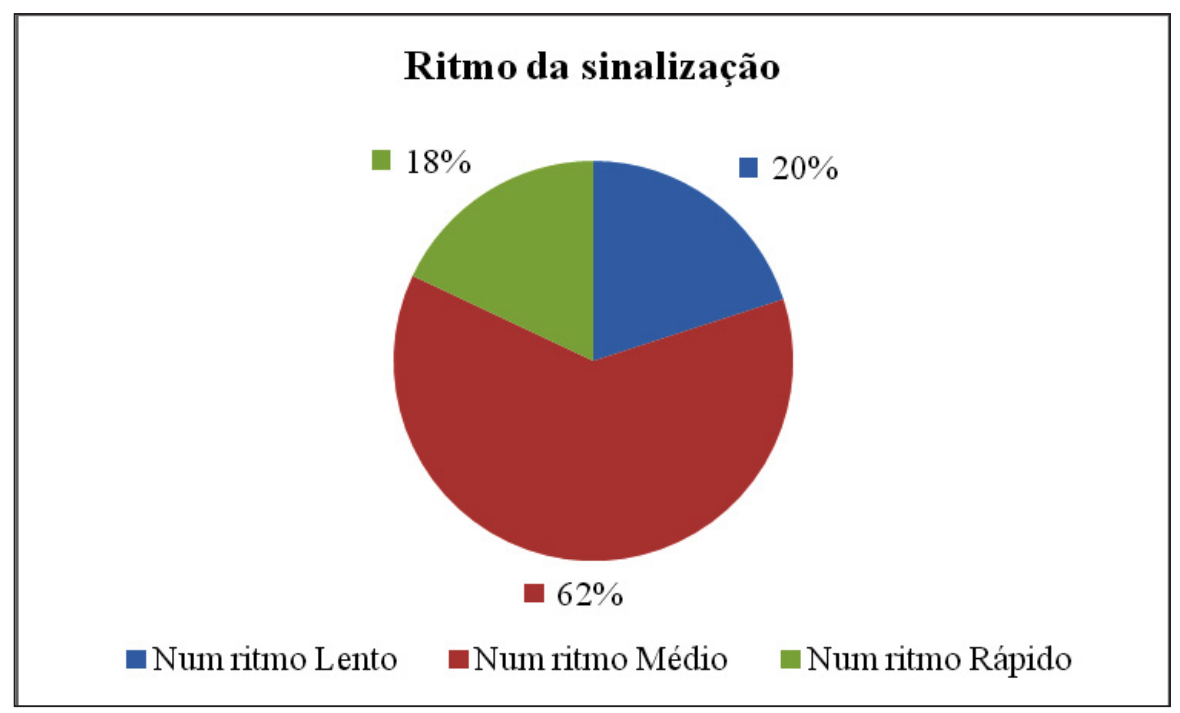

Gráfico 9 - Ritmo da sinalização 
Os dados de autoavaliação que temos até aqui nos mostram um público que sinaliza o tempo todo - ao menos que haja troca de turno com o interlocutor -, em uma velocidade 'normal', com pequeníssimas pausas e mesmo nesses ínfimos momentos que elas ocorrem há a produção do sinal de desculpa ou de novos sinais 'corretivos' e isso nos aponta uma problemática conceitual.

Uma problemática que advém do fato de que essa definição de fluência como fluir de sons, sílabas, palavras e frases ditas sem interrupções, as quais o ouvinte leigo classifica como normal é, generalistas e imprecisas, pois não é fácil definir o que o ouvinte leigo classificaria como normal ou o que é uma pausa aceitável. Embora de uma forma intuitiva tenhamos noção do que é falar em ritmo e com pausas normais, as investigações correntes, a maioria com viés quantitativo, esforçam-se para definir padrões, ao menos aproximados, de fluência na fala humana.

Forkamp (2003), por exemplo, apresenta variações metodológicas utilizadas para medir alguns constituintes da fluência da fala e procura dividir o número total de unidades semânticas proferidas (palavras completas ou parciais) incluindo as repetições, pelo tempo total, expresso em segundos, despendido na tarefa e dividi-lo por 60, expressando assim o número de unidades semânticas por minuto. A autora constata que as pausas podem variar de acordo com o critério adotado pelo pesquisador, mas que via de regra, são definidas em micropausas, hesitações e pausas não preenchidas. Para as primeiras há silêncio de menos de 2 segundos, para a segunda de 3 a 4 segundos e 5 ou mais segundos são classificados como pausas não preenchidas. Esse é um exemplo de tentativa de classificação, entretanto, parece não existir um consenso no tempo limite para determinar qual é a velocidade ou a pausa aceitável para uma boa fluência, nem um parâmetro comum compartilhado por testes.

Essas acepções advêm de constructos quantitativos de fluência, pois no viés qualitativo as pausas e hesitações podem ser consideradas estratégias utilizadas em determinados tipos de texto, como no exemplo 
analisado por Pawley e Syder (1983) em que um falante seguro e experiente ao falar em público, foi gravado durante sua defesa oral de $\mathrm{PhD}$, respondendo a questões sobre a integração fonológica de empréstimos linguísticos no sistema fonêmico de uma certa língua da Nova Guiné. O falante não demonstrava sinais de estresse nas suas respostas às arguições e sua fala parecia refletir a novidade do tema em questão e uma cuidadosa escolha de vocabulários em uma situação na qual a exatidão deveria ser preponderante a fluência. Esse acadêmico, se estivesse sendo avaliado quantitativamente poderia ser reprovado num teste de fluência. Vejamos então, como seria uma definição de fluência pela abordagem qualitativa.

A primeira definição de fluência, nesta concepção é de Lindblom (1990), que considera a precisão articulatória, e para sondar a articulação dos sinais produzidos pelos acadêmicos do Letras Libras, os perguntamos a respeito das falhas que comentem durante a realização de um sinal e eles disseram que erram na hora de formatar a mão para junta-la aos demais segmentos fonéticos-fonológicos.

\section{Erros fonéticos/fonológicos}

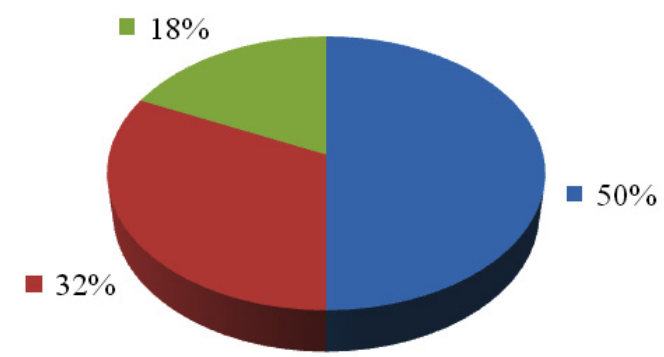

- Movimento do sinal

- Ponto de articulação do sinal

• Configuração do sinal

\section{Gráfico 10 - Erros fonéticos/fonológicos}


Cometer erro na hora de configurar um sinal pode comprometer, sobremaneira o entendimento, do interlocutor uma vez que o emissor demonstra, nesse caso, falta de fluência. Isso quer dizer que se um ouvinte falante de Libras como segunda língua acertar a configuração de mão, mas errar o movimento, o sinal pode ser facilmente identificado pelo interlocutor fluente uma vez que temos uma número limitado de movimentos possíveis em Libras e associação com o segmento corretamente produzido facilita a junção pelo contexto. Da mesma forma, caso o emissor acerte a configuração de mão, mas erre o ponto de articulação, o sinal pode ser facilmente identificado pelo interlocutor fluente uma vez que em Libras, somente alguns pontos são permitidos e dessa forma a associação com o segmento corretamente produzido facilita a junção pelo contexto. Entretanto, se o emissor errar a configuração de mão, o interlocutor terá dificuldade para entender o sinal, pois existem inúmeras configurações de mão no mesmo ponto e dedução fica muito mais comprometida.

Outra definição de fluência é posta por Forkamp (2003), para quem a densidade lexical é um importante fator para identificação da fluência. Para esta autora, ser fluente implica em ter repertório de vocabulário suficientemente complexo a fim de que se possa desenvolver discursos mais elaborados, entretanto, em nossa pesquisa, apenas 19\% dos entrevistados diz utilizar-se de vocabulários de complexidade elevada. 


\section{Complexidade dos vocabulários}

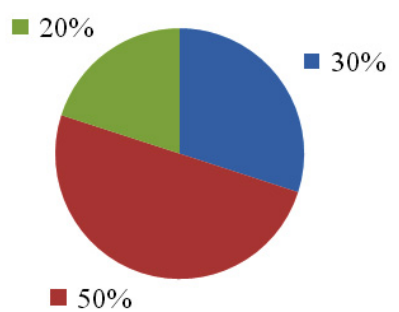

- Baixa complexidade

- Média complexidade

Complexidade elevada (sinais técnicos)

Gráfico 11 - complexidade dos vocabulários

Até aqui temos razões quantitativas e qualitativas para asseverar algum nível de disfluência nos acadêmicos do Letras Libras, mas prossigamos com a conceituação. Merlo (2006) aponta que a facilidade - não a rapidez - de emissão é um importante fator a ser considerado na fluência. Ela define a facilidade de emissão como pouco esforço e suavidade na emissão da fala. Para observar esta variável da concepção qualitativa, perguntamos aos acadêmicos como eles avaliam o esforço que empregam para sinalizar, uma vez que estamos entendendo que pouco esforço seria sinônimo de facilidade de expressão. As respostas que obtivemos foram as apresentadas abaixo: 


\section{Facilidade de expressão}

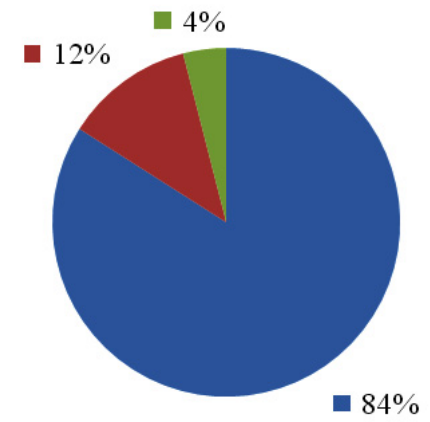

—Pouco esforço físico $\square$ Muito esforço físico $\square$ Nenhum esforço físico

\section{Gráfico 12 - Facilidade de expressão}

Se a concepção adotada para medida de fluência dos acadêmicos ouvintes do Letras Libras for advinda de Merlo (2006) poderemos considerá-los fluentes e não mais disfluentes como anteriormente apontado. Tal antagonismo nos leva a relativizar o conceito de fluência, uma vez que Finn \& Ingham (1991) apontam que essa definição não deixa claro se ela identifica uma fala que os ouvintes interpretariam como fluente nem se tal definição se refere a fala normalmente fluente. Isto é, parece que a produção e o produto da fluência demandariam, desde o princípio, especificidades de abordagem e, portanto, de definição ou domínio. A dicotomia está proposta desde o início, na assunção de que o que o ouvinte interpreta como fala fluente deve se distinguir necessariamente da fala normalmente fluente.

Outra afirmação intrigante na área, que revela a dificuldade de se lidar com este tópico é a de que fluência parece ser um fenômeno de fácil compreensão, mas cuja noção é resistente a uma definição direta e não ambígua. A perplexidade dos estudiosos aumenta quando se perguntam a 
que traços audíveis e visuais tal presumida facilidade de reconhecimento se compatibiliza, se inegavelmente, segundo os autores, nós temos uma ideia na nossa mente do que seja fluência e podemos reconhecer quando vemos e ouvimos. Em outras palavras, sendo os traços de fluência/disfluência tão materiais e comportamentais, a falta de uma mensuração adequada complica ainda mais sua definição, segundo autores. Dessa forma que desconfiam que os significados vinculados ao termo estendem-se para além da produção dos enunciados.

Desta decorre outra afirmação corrente, a de que a fluência deve ser encarada como um barômetro para o sistema de fala como um todo, cujos limites são estabelecidos pela adequação do desempenho das dimensões semântica, sintática, morfêmica e prosódica da fala. Sem nos perguntarmos o que os autores entendem por dimensões semânticas, sintática e morfêmica da fala, o fato é que apesar de que o espaço privilégio para ocorrência do fenômeno em questão seja a fala, o que ocorre é que na quase impossibilidade de se mapearem adequadamente os aspectos mensuráveis da fluência concluem que as dificuldade advém do fato de que os fenômenos em questão ora são considerados como pertencentes a fala, ora a linguagem. Passemos agora à segunda categoria de triangulação dos dados.

\section{Acurácia gramatical em ouvintes usuários de Libras como segunda língua}

Brumfit (1979) diz que acurácia é a habilidade do falante em produzir frases em conformidade com exigências fonológicas, sintáticas e semânticas em uma dada língua natural. Isso quer dizer que os lapsos gramaticais são percebidos, algumas vezes, como falta de fluência linguística. Uma maior habilidade na gramática repercute na segurança com que a fala é emitida, pois a automatização de estruturas gramaticais 
complexas, principalmente em L2, acelera a velocidade da fala e torna pausas e hesitações menos frequentes. Tendo por base essa premissa, e pautando-nos em estudos linguísticos que mais se tem conhecido sobre esta língua e, no Brasil, especialmente Quadros e Karnopp (2004) que apresentam descrição da Libras em nível fonológico, morfológico e sintático, é que fazemos as considerações sobre acurácia.

Vejamos, o que os acadêmicos do Letras Libras responderam à pergunta: "Você conhece a gramática da Libras?"

\section{Conhecimento da gramática da Libras}

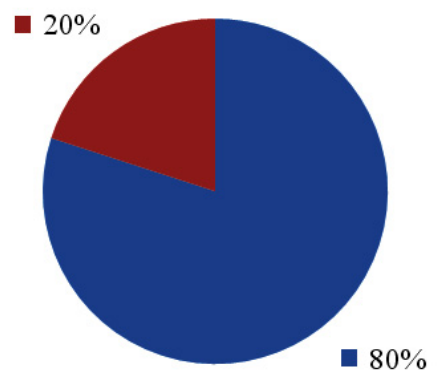

- Sim - Não

Gráfico 13 - Conhecimento da gramática da Libras

É muito interessante olhar para este dado uma vez que a maioria dos acadêmicos questionados está na metade do curso, ou seja, ainda falta algum tempo para concluírem seus estudos e o ensino da gramática, conforme apresentado no currículo do Curso, é dissolvido pelos quatro anos. Tais dados não eram esperados de alunos de períodos iniciais, ou seja, pensamos que eles não iam responder que sabiam a gramática da Libras, como ocorreu com mais de $80 \%$ da amostra.

Ainda que sejam usuários fluentes Libras, uma vez que fizeram vestibular e foram aprovados, causa certo estranhamento a demonstração 
de segurança frente a uma pergunta tão global que envolve inúmeros desdobramentos como o próprio conceito de gramática. Os acadêmicos não fizeram nenhuma intervenção a respeito de que gramática estávamos falando e nenhum apontamento sobre especificidades gramaticais. O que parece é que houve uma resposta ingênua frente a um tópico tão delicado como esse.

Apesar da resposta sugerir falta de clareza quanto ao termo gramática e a tudo que ele engloba, podemos ainda problematizar a acurácia desses acadêmicos uma vez que conhecer a gramática não implica em, necessariamente, usá-la adequadamente. Para medir tal feito, outros testes seriam necessários e não o temos em mãos. Isso quer dizer que o fato dos alunos se autoavaliarem como conhecedores da gramática da Libras não nos permite ainda asseverar que sejam acurados. Seguindo essa linha de raciocínio, pensemos: o que leva $54 \%$ dos acadêmicos investigados se autoavaliarem positivamente diante da pergunta "Você acha que sinaliza com precisão gramatical?"

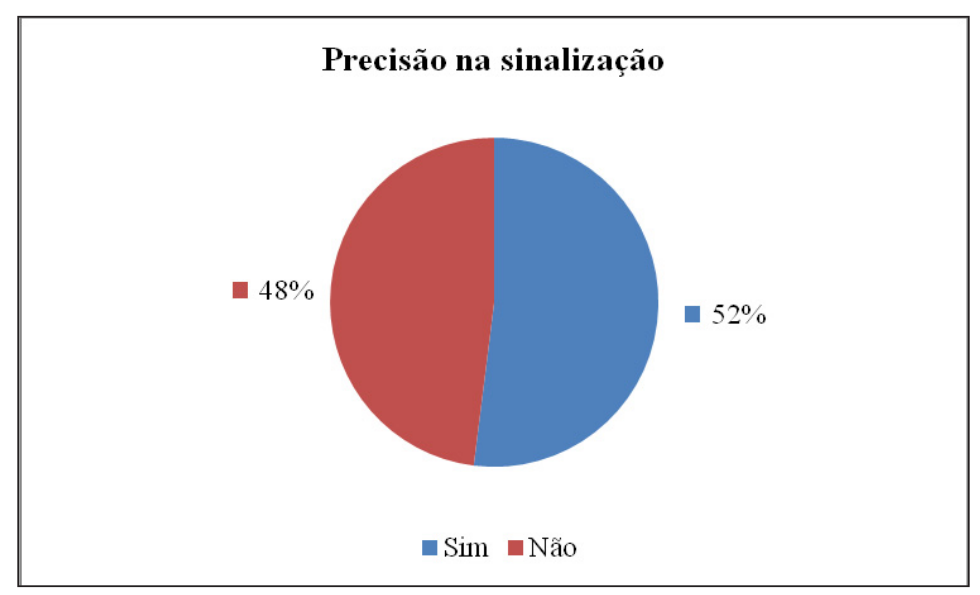

Gráfico 14 - Precisão na sinalização 
O que nos instiga aqui é a resposta direta frente a uma pergunta que merecia ser relativizada, pois mesmo que nosso método não tenha dado conta de dar a expressividade necessária para observações do participante, nossas anotações pessoais estariam registradas as manifestações atitudinais frente ao instrumento. Para problematizar ainda mais um pouco, vejamos o resultado em relação à pergunta que tratava da dificuldade de produção da expressão facial.

\section{Dificuldade de produção da expressão facial}

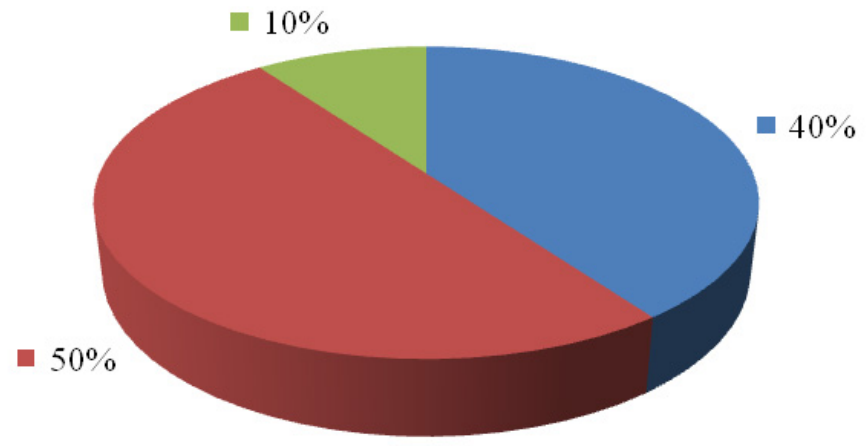

Pouca dificuldade $\quad$ Muita dificuldade $\quad$ Nenhuma dificuldade

Gráfico 15 - Dificuldade de produção da expressão facial

O nível fonológico da Libras é composto por três componentes da estrutura interna dos sinais, os quais são: Configuração de mão (CM), Localização (L) e Movimento (M). Isoladamente, esses parâmetros não têm conteúdo algum, porém quando os unimos podemos formar conteúdos irrestritos. O primeiro parâmetro - configuração de mão - refere-se à forma que a mão assume na realização do sinal. Algumas destas configurações de mão correspondem às letras do alfabeto manual, mas não se restringem a elas. Para as configurações de mão da Libras, temos um registro de 64 (sessenta e quatro) possibilidade de formas que podem dar origem a sinais 
da Libras se forem produzidas apenas com uma mão, com duas mãos com a configuração de mão diferente, ou ainda com as duas mãos com configurações de mão iguais.

O segundo parâmetro fonológico da Libras - a locação ou ponto de articulação - apontado por Quadros e Karnopp (2004) refere-se ao espaço onde o sinal será realizado, podendo ser no próprio corpo do sinalizador ou no espaço neutro (espaço 'vazio' a frente do corpo do sinalizador, precisamente entre a cabeça e o quadril). Dentro desse espaço de enunciação, pode-se determinar um número finito (limitado) de pontos, que são denominados 'pontos de articulação'. Alguns pontos são mais precisos, tais como a ponta do nariz, e outros são mais abrangentes, como a frente do tórax. O espaço de enunciação é um espaço ideal, no sentido de que se considera que os interlocutores estejam face a face.

O terceiro principal parâmetro - o movimento - é bastante complexo, considerando a vastidão de possibilidades. Em Strobel e Fernandes (1998) vemos que estes movimentos podem ser do tipo sinuoso, semicircular, circular, retilíneo, helicoidal e angular, sendo possível produzilos de forma unidirecional, bidirecional ou multidirecionalmente. Além disso, eles podem ser produzidos com diferentes tensões, velocidades e frequência. Battison (1974) falando sobre os movimentos, apresenta duas restrições. A primeira restrição é a condição de dominância e a segunda é a condição de simetria. Por condição de dominância, o autor entende a ocorrência de sinais nos quais uma das mãos assume o papel ativo e a outra, um papel passivo. A mão passiva, neste caso, serve de base, de apoio para a realização do movimento da mão ativa. E no caso de sinais com duas configurações de mãos iguais ativas e realizam o mesmo movimento há a condição de simetria estabelecida

Além destes parâmetros, Quadros e Karnopp (2004) destacam a orientação da mão e as expressões não-manuais. A orientação de mão é a direção que a palma da mão assume na realização do sinal. A palma da mão pode estar voltada para cima, para baixo ou para o corpo de quem 
sinaliza, para fora, para a esquerda e para a direita. As expressões nãomanuais, referem-se às expressões faciais e aos movimentos do corpo produzidos durante a realização do sinal ou realizados isoladamente para marcar construções sintáticas - marcar sentenças interrogativas, relativas, concordância, tópico e foco, marcar referência específica, referência pronominal, negação, advérbios, grau ou aspecto bem como para marcar afetividades, conforme ocorre nas línguas naturais. Quadros, Pizzio e Rezende (2008) dizem que há dois tipos de expressões faciais: as gramaticais e as afetivas. As autoras explicam que as primeiras são utilizadas para expressar sentimentos (alegria, tristeza, raiva, angústia, entre outros) e podem ou não ocorrer simultaneamente com um ou mais itens lexicais. Já as expressões gramaticais, estão relacionadas a certas estruturas específicas, tanto no nível da morfologia quando no nível da sintaxe e são obrigatórias nas línguas de sinais em contextos determinados.

A questão que fica até aqui é a seguinte: como 50\% dos participantes podem ser acurados se 50\% deles tem dificuldade com a expressão facial que é um importante parâmetro fonológico da Libras? Ou os participantes não tiveram seriedade para participar da pesquisa, no sentido dar respostas aleatorias, ou então estamos frente a uma séria denúncia de falta de coerência entre a prática e a autoavaliação destas pessoas.

Avançando um pouco mais, temos o parâmetro morfológico e daí constatamos que $70 \%$ dos conhecedores da Libras têm alguma dificuldade com a produção de concordância verbal. 


\section{Dificuldade de produção da concordância verbal}

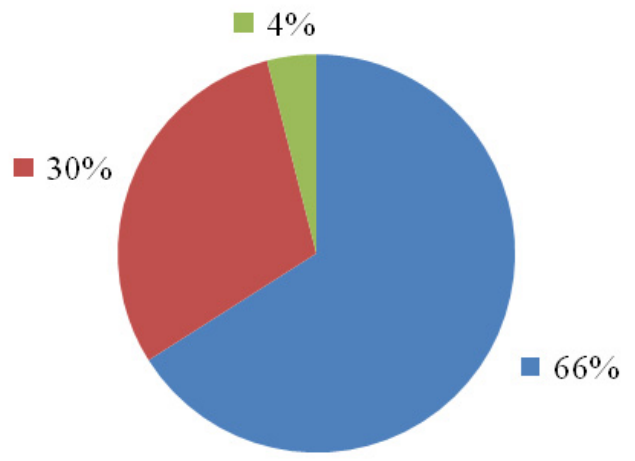

- Pouca dificuldade $\quad$ Muita dificuldade $\quad$ Nenhuma dificuldade

Gráfico 16 - Dificuldade de produção da concordância verbal

Em relação a este nível, Quadros e Karnopp (2004) apontam os tipos de verbos: A) verbos simples - são verbos que não se flexionam em pessoa e número e não incorporam afixos locativos. Alguns desses verbos apresentam flexão de aspecto. Todos os verbos ancorados no corpo são simples. Há também alguns que são feitos no espaço neutro. Exemplos dessa categoria são CONHECER, AMAR, APRENDER, INVENTAR, GOSTAR. B) verbos com concordância são verbos que se flexionam em pessoa, número e aspecto, mas não incorporam afixos locativos. Exemplos dessa categoria são DAR, ENVIAR, RESPONDER, PERGUNTAR, DIZER, VER que são subdivididos em concordância pura e reversa. Os verbos com concordância apresentam a direcionalidade e a orientação. A direcionalidade está associada ás relações semânticas. A orientação da mão voltada para o objeto da sentença está associada à sintaxe. C) verbos espaciais são verbos que tem afixos locativos. Exemplos dessa classe são IR, CHEGAR. D) verbos manuais são verbos que usam classificadores e 
incorporam a ação. Exemplos dessa categoria são COLOCAR-BOLONO-FORNO e SENTAR-NO-MURO.

Da mesma forma, entendemos que os fenômenos gramaticais do nível morfológico precisavam ser produzidos conforme as autoras descrevem para a Libras, mas o que parece é que se ainda há alguma dificuldade, o que nos leva a crer que a produção da concordância verbal deva ocorrer somente esporadicamente e não constantemente como com sinalizadores fluentes.

E em relação ao nível sintático, as autoras discutem o processo de referenciação, já que a Libras estabelece a maioria de sua organização sintática no espaço. Em Libras temos o espaço real e o espaço mental (espaço sub-rogado e o espaço token). O espaço sub-rogado é resultante da integração do corpo do sinalizador com entidades do espaço do evento e o espaço token é restrito ao espaço a frente do sinalizador. Para se referir a dois grupos, por exemplo, o sinalizador cria a integração de dois espaços mentais: o espaço real e o espaço do evento que está narrando. Cada uma das localizações corresponde a um dos grupos. O número de tokens em um discurso pode variar. Tanto no caso de integrações sub-rogadas como tokens, a compreensão do discurso pelo destinatário está condicionada ao reconhecimento de qual espaço mental está ativo em cada momento. Além disso, a referência do apontamento pode se dar tanto para entidades do espaço real ou para o espaço subrogado, isto é, entidades criadas através da integração do espaço real com o espaço do evento, fornecendo instruções para que o destinatário consiga fazer a conexão com a entidade referida.

Quadros, Pizzio e Rezende (2009) dizem que quando o referente não estiver presente, ou temporariamente ausente, a apontação é direcionada a um local espacial arbitrário, ao longo do plano horizontal, defronte ao corpo do sinalizador. A referência anafórica requer que o sinalizante aponte (olhe ou gire o corpo) a um local previamente estabelecido, isto é, após a introdução de um nominal co-referente a um 
ponto estabelecido no espaço, este ponto no espaço referir-se-á àquele nominal, mesmo depois de outros sinais serem introduzidos no discurso. Um fenômeno muito comum nos discursos sinalizados e que também aparece em discursos orais é a ação construída. Em ações construídas, parte do corpo do sinalizador se movimenta de maneira a representar iconicamente o corpo de uma personagem, ou para representar a localização, o posicionamento e a movimentação de algum objeto ou entidade. Nesse sentido, para compor ações construídas, o sinalizador pode fazer uso de expressões faciais, posturas do tronco, posição da cabeça e fundamentalmente direção do olhar.

Ponderando isso, percebemos que no questionário de autoavaliação, os acadêmicos dizem ter problemas para lidar com os elementos que constroem sentenças em Libras. É o caso de $80 \%$ dos entrevistados se autoavaliarem com dificuldade em relação à ordem da frase em Libras, de $65 \%$ dos entrevistados pode ter dificuldade para falar de referentes não presentes e de 64,3\% não se dizerem aptos para fazer incorporação que é um dos recursos básicos da sinalização.

\section{Dificuldade em relação à ordem da frase}

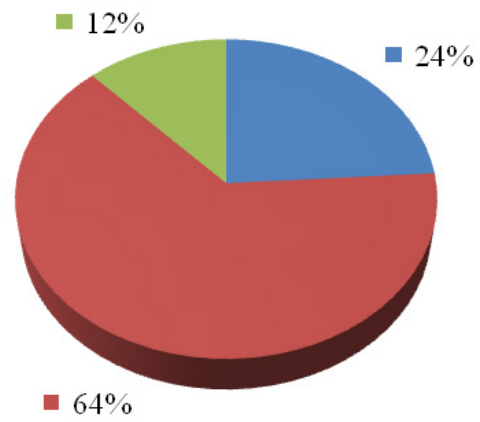

- Pouca dificuldade $\quad$ Muita dificuldade $\quad$ Nenhuma dificuldade

Gráfico 17 - Dificuldade em relação à ordem da frase 
E esta dificuldade foi reafirmada quando inquirimos os acadêmicos sobre a estrutura sintática que mais utilizavam durante a sinalização.

\section{Estrutura sintática mais utilizada}

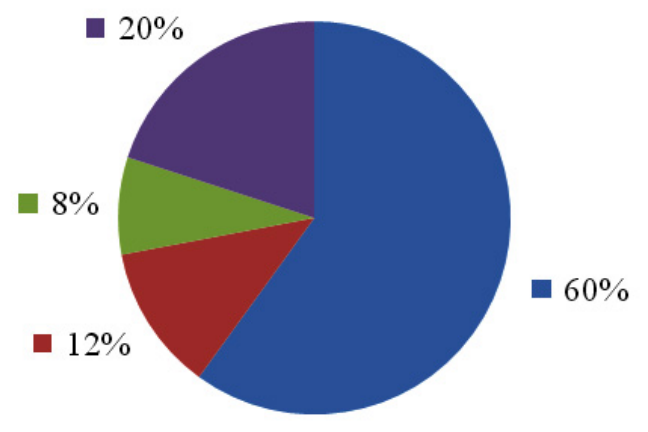

—SVO —Tópico-comentário —VOS — Não sei

Gráfico 18 - estrutura sintática mais utilizada

Se $60 \%$ dos acadêmicos ouvintes utilizam predominantemente a ordem canônica do português para construírem sentenças em Libras que é uma língua espaço-visual, e por isso mesmo de característica tópicocomentário, então é possível que a sinalização não esteja acurada conforme eles se autoavaliaram. 


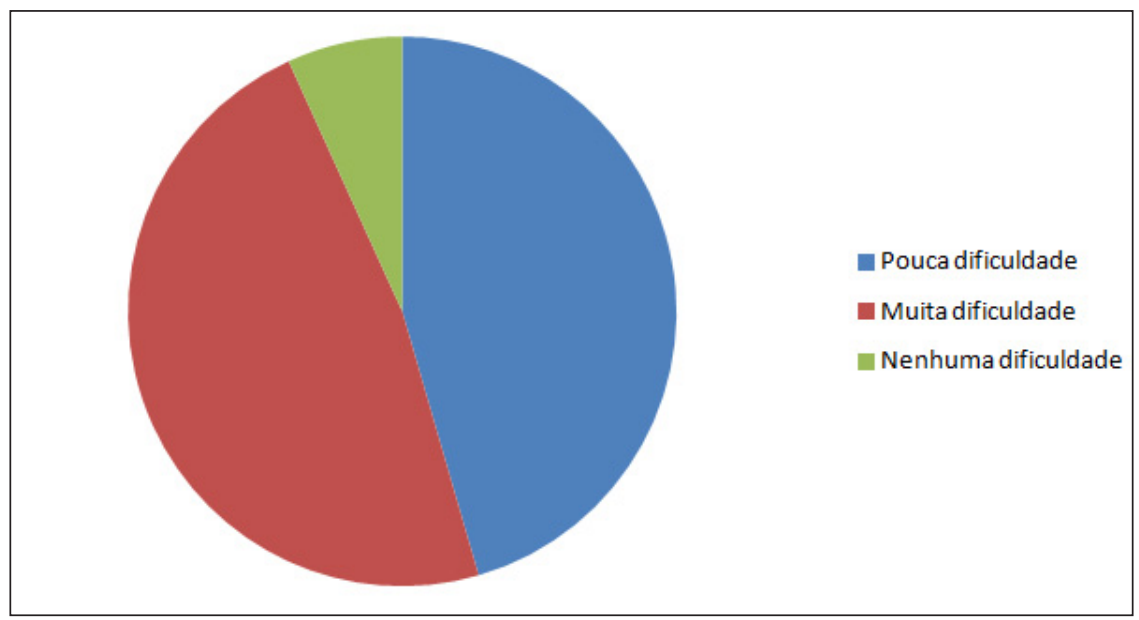

Gráfico 19 - Dificuldade em relação à produção de referentes ausentes

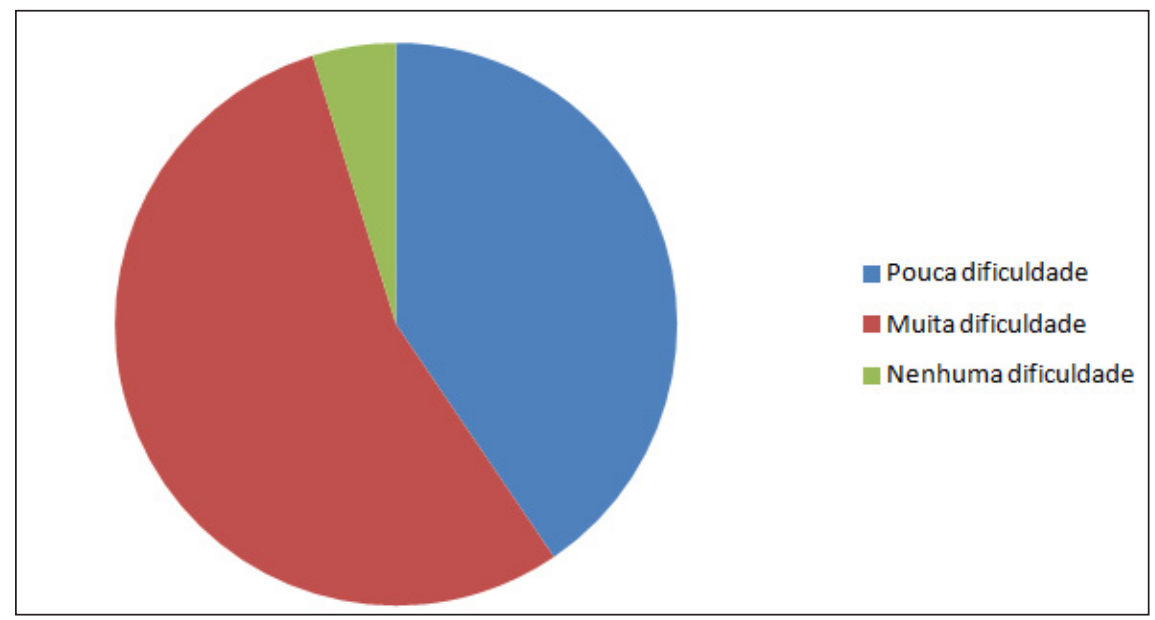

Gráfico 20 - Dificuldade em relação à incorporação

Ainda em relação a constatação da produção sintática, perguntamos "Você acha que suas ideias são encadeadas em Libras, ou seja, você usa estratégias discursivas de retomada, reforçamento de 
ideias, ligação entre parágrafos?” E as respostas que obtivemos foram na sua maioria de que sim.

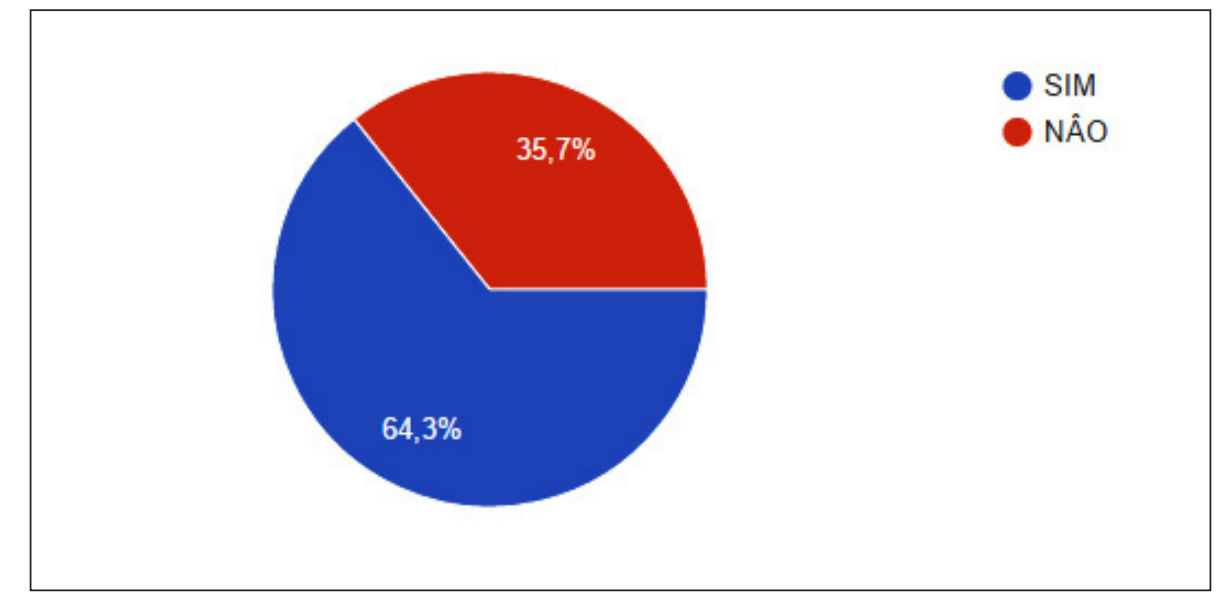

Gráfico 21 - Encadeamento de ideias

Este dado nos parece contraditório com o anterior, uma vez que é a numa sinalização com ideias encadeadas, os referentes são adequadamente postos no espaço, as ações construídas são bem formuladas e a frase obedece a característica visual e simultânea da Libras. Como podem as pessoas encadear ideias, usar estratégias de retomada ou reforçamento sem ter domínio do uso dos referentes ausentes?

\section{Considerações finais}

A partir dos dados coletados, foi possível cumprir o objetivo proposto para este trabalho, ou seja, cruzamos as respostas de autoavaliação sobre fluência e acurácia dos acadêmicos do Letras Libras com as abordagens teóricas destes conceitos e encontramos resultados interessantes. 
Primeiramente, pudemos contatar que diferentes conceitos podem enviesar a atribuição do rótulo de fluência dos ouvintes acadêmicos do Letras Libras. Assim, se olharmos pelo ponto de vista da velocidade e da facilidade da sinalização avaliaremos que a maioria deles apresenta fluência, mas se considerarmos a precisão articulatória e o uso de vocabulários mais elaborados, então não poderemos atribuir-lhes fluência. Aqui nos restam algumas reflexões: 1) A adoção de conceito norteador seria facilitador para averiguar a fluência dos ouvintes acadêmicos do Letras Libras?; $\mathrm{Na}$ ausência de um conceito fixo, quais são as estratégias utilizadas pelos professores do referido curso para avaliar o nível de fluência dos ouvintes acadêmicos do Letras Libras?; Qual seria a marca diferencial da sinalização do ouvinte ingressante no Letras Libras para o egresso do curso que, está habilitado para ensinar e/ou traduzir e interpretar nessa língua?

Ao que parece as respostas antagônicas dada em autoavaliação pelos ouvintes refletem o conhecimento que têm sobre o tema e, considerando que são acadêmicos podemos entender que esse tem sido o conhecimento que tem circulado (ou não) no Curso e, seguindo o efeito dominó, provavelmente, este é o aparato teórico que a ciência apresentou aos professores/pesquisadores do Letras Libras. Com isso, coloca-se aos estudos linguísticos o desafio urgente de aprofundar a questão da fluência em Libras de modo que, em havendo se estabelecido o entendimento teórico, ele possa ser inserido no lócus de formação de segunda língua dos acadêmicos ouvintes.

Além disso, também observamos que parece haver algum equívoco nas respostas dos alunos, pois eles se autoavaliam como conhecedores da gramática e precisos na sinalização, mas alegam dificuldade na produção no que diz respeito aos níveis fonológico, morfológico e especialmente o sintático. Ao que parece, a postura de autodeclaração dos acadêmicos acerca da sua acurácia em Libras termina assim que se especificam as perguntas. Com isso, coloca-se a necessidade aos alunos de uma autocrítica a respeito da sua produção, bem como o ensino explícito dos elementos que compõe a acurácia da língua. 


\section{Referências Bibliográficas}

BATTISON, R. (1974). Phonological deletion in American Sign Language. Sign Language Studies, v. 5, 1974.

BRASIL. Decreto n. 5.626 de 22 de dezembro de 2005. Regulamenta a Lei n. 10.436 de 24 de abril de 2002, que dispõe sobre a Língua Brasileira de Sinais - Libras.

BRASIL. Lein 10.436 de 24 de abril de 2002. Dispõe sobre a Língua Brasileira de Sinais - Libras e dá outras providências.

BRUMFIT, C The communicative approach to language teaching. Oxford University Press. Oxford, 1979.

FINN, Patrick \& INGHAM, Roger. The selection of "fluent" samples in research on stuttering: conceptual and methodological considerations. In Healey, Ch (org.). Readings on research in stuttering. Nova Iorque: Longman Publishing Group, 1991, p. 91-109.

FONSECA, J. J. S. Metodologia da pesquisa cientifica. Fortaleza: UEC, 2002. Apostila.

FORTKAMP, Mailce Borges Mota. Working memory capacity and fluency, accuracy, complexity and lexical density in L2 speech production. Florianopólis: Fragmentos. V 24, p. 69-104, 2003.

LINDBLOM, B. Phonetic variation and selection. PERILUS XI. 1990.

MERLO, S. Hesitações na fala semi-espontânea: análise por séries temporais [mestrado]. Campinas (SP):Departamento de Lingüística, Universidade Estadual de Campinas; 2006. 
PAWLEY, A. AND SYDER, F.H., 1983. Two puzzles for linguistic theory: nativelike selection and nativelike fluency. In: J.C. RICHARDS AND R.W. SCHMIDT, eds. Language and communication.London: Longman.

QUADROS, R.M. e KARNOPP, L.B. 2004. Lingua de sinais brasileira: estudos linguísticos. Porto Alegre, Artmed.

QUADROS, R. M.; PIZZIO, A. L.; REZENDE, P. L. F. Lingua Brasileira de Sinais II. Universidade Federal de Santa Catarina Centro de Comunicação e Expressão (CCE) Centro de Educação (CED) Licenciatura em Letras/ Libras na Modalidade a Distância. Florianópolis: 2008.

SCARAMUCCI, M.V.R. Proficiência em LE: considerações terminológicas e conceituais. Trabalhos de Lingüistica Aplicada 36, p. 11-22. 2000.

SIGNORINI, Inês. Por uma teoria da desregulamentação lingüistica. In: Bagno, Marcos (org.) A Lingüística da Norma. São Paulo: Edições Loyola, 2002, p. 93-125.

SILVA, Vera Lucia Teixeira. Fluência oral: imaginário, construto e realidade num curso de Letras - Campinas, SP: [s.n.], 2000.

STRÖBEL, K. L.; FERNANDES, S. Aspectos lingüísticos da LIBRAS: Lingua Brasileira de Sinais.Curitiba: SEED : DEE, 1998.

SKEHAN, P.; FOSTER, P. Cognition and tasks. In: ROBINSON, P. Cognition and second language instruction. Cambridge: Cambridge University Press, 2001. 